\title{
EFFECT OF STARCH AND CARBOXYMETHTYL CELLULOSE ON PHYSICO-CHEMICAL PROPERTIES OF TOMATO JUICE
}

\author{
M. S. Mahomud, S. Islam, M. N. Islam and M. A. Ashraf ${ }^{1}$ \\ Department of Food Technology \& Rural Industries, Bangladesh Agricultural University \\ Mymensingh-2202, Bangladesh
}

\begin{abstract}
This study was conducted to evaluate the effect of carboxymethyl cellulose (CMC) and starch used as thickening agents on physicochemical properties of tomato juice. The pulp was extracted from ripe and sound tomatoes and subsequently used for preparation of tomato juice with the addition of different levels of starch and CMC including other ingredients. The CMC was used at the rate of $0.1-0.3 \%$ while starch was $0.3-1 \%$ in the prepared juice. The moisture content of juice was increased adding of both the thickening agents. The ash content and acidity of tomato juice were decreased gradually with the increasing level of starch and CMC. The highest ash content and acidity were found in juice without added starch and CMC. The lowest ash and acid content was found in the juice incorporated with $1 \%$ and $0.3 \%$ starch and CMC respectively. Ascorbic acid was decreased with the increase of both thickening agents. The prepared juice was remained unchanged within two months. After two months, colour and flavour were changed and various bacterial load was increased.
\end{abstract}

Key Words : Tomato juice, Carboxymethtyl cellulose, Starch, Thickening agent

\section{INTRODUCTION}

Among the vegetables tomato (Lycopersicon esculentum) is an important crop owing to its inexpensiveness and valuable nutrient contents. It is abundantly growing in Bangladesh. The total production of tomatoes was 103000 metric tons in Bangladesh in the year of 2001-02 (BBS, 2004). The best growing areas of tomatoes are Chittagong, Comilla and Rajshahi in Bangladesh (Sharfuddin and Siddique, 1985). Tomatoes are easily available during the months of March and April. It is highly perishable and spoils within a few days after harvesting. It needs immediate action for proper preservation and storage to maintain its freshness. Hence proper preservation and storage in raw state or fresh form or convert it in a form of other products is essential. However, if the farmers are unable to do these, they are bound to sell their product at lower price during the peak season. Since the tomato is seasonal crop, hence, in off-season the peoples devoid of tomato based nutrients. So these nutrients could be made available throughout the year if the tomato could be preserved intact or in any processed

1Department of Farm Structure, Bangladesh Agricultural University, Mymensingh, Bangladesh 
form without disturbing its nutrient contents upto the next harvesting season. It is difficult to preserve tomato intact because of its perishability. The easier way to preserve it in the form of processed product.

Storage facilities of this crop are not adequate. Hence there is a market glut during the peak season and price falls down to the production cost. Hence it needs an immediate action for preservation and storage to maintain its freshness.

The objectives of these attempts are: i) to formulate a tomato juice using starch/CMC as thickening agents, ii) to study its shelf life and iii) to find its acceptability. To fulfill these objective data of nutrition properties, microbial load and physical properties of the tomatoes will be taken, because the nutritional properties includes the nutrient contents of fresh and processed juice like vitaminC, carbohydrate, ash, acidity; the microbial load includes the growth and activity of mold and bacteria at a certain interval of tune; and the physical properties include the colour, texture, flavour, taste, acceptability, stickiness or fluidity, which will be assessed by organoleptic-taste testing panel.

\section{MATERIA LS AND METHODS}

The experiment was conducted in the laboratories of the Department of Food Technology and Rural Industries, Bangladesh Agricultural University, Mymensingh during the period c $f$ January to June 2006.

The mature, fresh tomatoes were collected from the local market. In the experiment, the pulp of tomatoes was used. Citric acid, potassium meta bisulphate (KMS), carboxy methyl cellulose (CMC), sugar and other materials required were used from the laboratory stock.

\section{Extraction of tomato juice and pulp}

Fully matured ripen, sound, deep-red colored fresh tomatoes were collected and washed thoroughly. The stems, cavities as well as the green and yellow portions were removed from the tomatoes. These were then cut into small pieces and boiled for about 90 minutes and crushed with wooden ladle to extract maximum pulp. The crushed boiled material was strained through a bamboo or aluminum sieve by rubbing with a clean bottom mug. The seed and skin were discarded. The pulp thus prepared was stored and used for future use.

\section{Treatment of tomato juice}

The juice was treated with two types of thickening agents in different proportions to increase the consistency or viscosity of the juice. The calculated amount of sugar, acid, and salt was added. The preparation flowchart of tomato juice is shown in Fig. 1. 
Table 1. Tomato juice heated with starch and CMC (Thickeners)

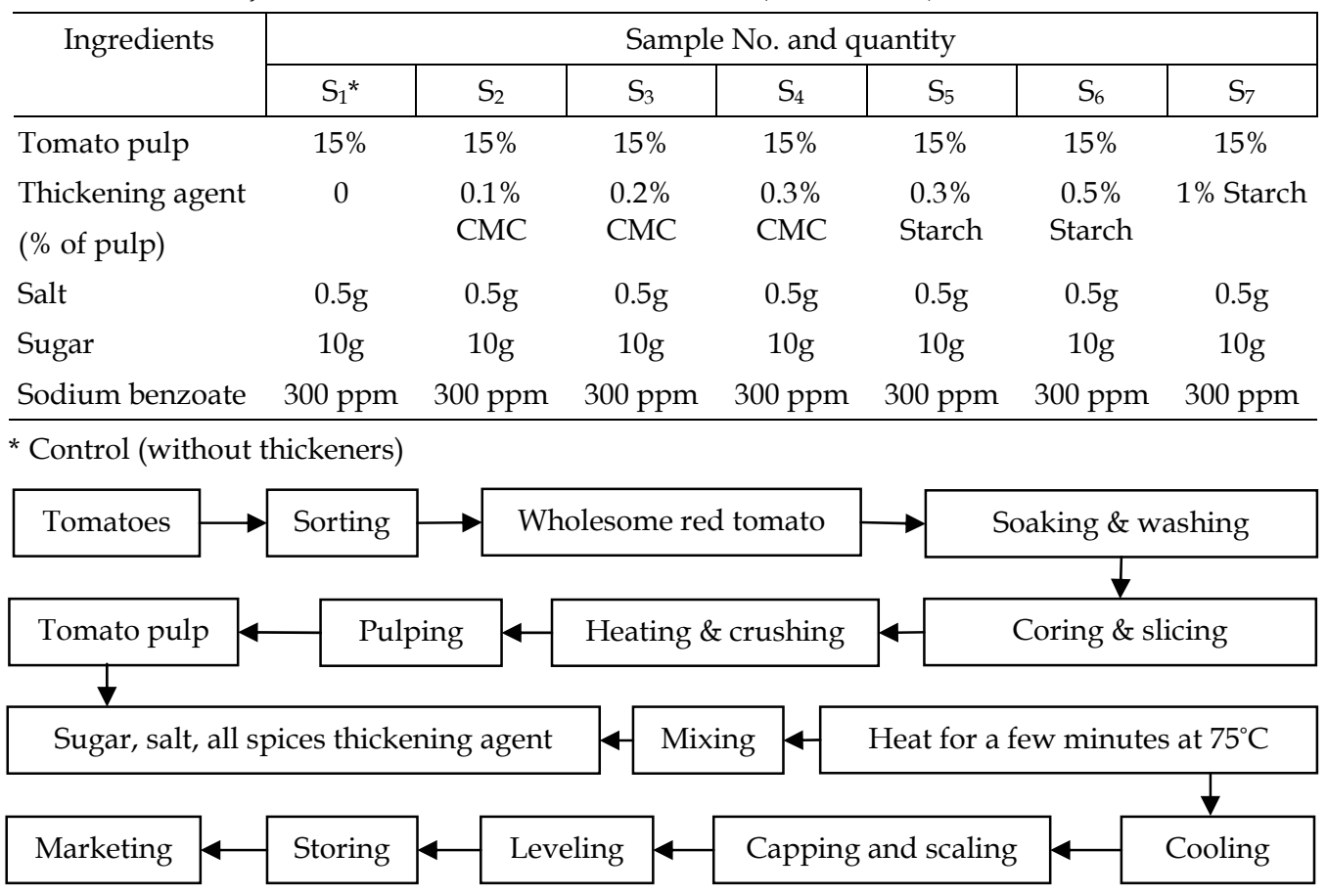

Fig. 1. Preparation flowchart of tomato juice

\section{Analysis of initial pulp/juice}

The analyses were done following the standard methods of Rangana (1979), AOAC (2000) and Lane and Eynon (1923). The initial tomato juice were analyzed for total soluble solid (TSS), acidity, $\mathrm{pH}$, ascorbic acid and ash content.

\section{RESULTS AND DISCUSSION}

The tomato juice is a condiment prepared from tomato pulp, salt, sugar and water. The fresh pulp and processed juice was analyzed for nutritional properties, microbial load and physical properties.

\section{Nutritional properties}

The tomato pulp was used to formulate tomato juice, which was analyzed for proximate composition. The results are shown in Table 2.

From the Table 2, it was observed that the nutrients present in the pulp was not similar to the nutrients the processed tomato juice. Here, ascorbic acid of the processed juice was decreased than that of the fresh tomato juice. 
Table 2. Approximate composition of tomato juice (per $100 \mathrm{gm}$ )

\begin{tabular}{l|c|c}
\hline \multirow{2}{*}{ Components } & \multicolumn{2}{c}{ Amounts } \\
\cline { 2 - 3 } & Fresh pulp/Raw & Processed juice \\
\hline Moisture & 94.68 & 95.2 \\
Ash & 0.4 & 0.4 \\
Acidity & 0.03 & 0.5 \\
pH & 4.01 & 3.43 \\
Ascorbic acid (mg) & 18.27 & 2.24 \\
\hline Total soluble solid & 4 & 12 \\
\hline Total sugar & 3.48 & 10 \\
\hline
\end{tabular}

Effect of CMC on composition of tomato juice

From Fig. 2 it was found that vitamin C (ascorbic acid) in tomato juice was reduced with the addition of $\mathrm{CMC}$ as well as with the increase of storage period, because it follows the first reaction kinetic (Heldman, 1974). The content of vitamin C for $0.1 \%$ CMC was almost same to that of the controlled condition.

Fig. 3 shows that $\mathrm{pH}$ level in tomato juice was increased with the addition of increasing level of $\mathrm{CMC}$, but it remained almost unchanged with the increase of storage period.

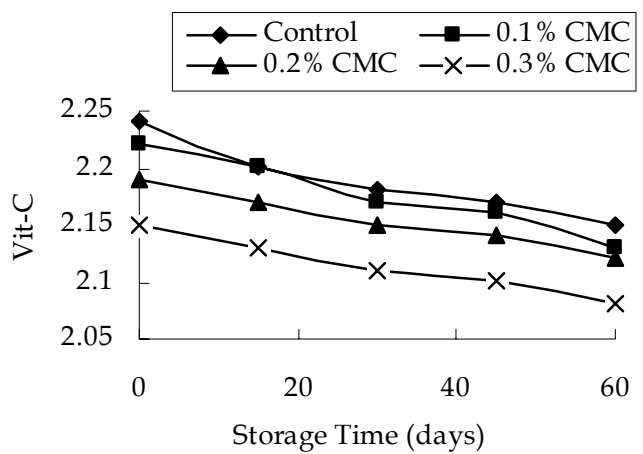

Fig. 2. Effect of different percentages of CMC on Vit-C for various storage time

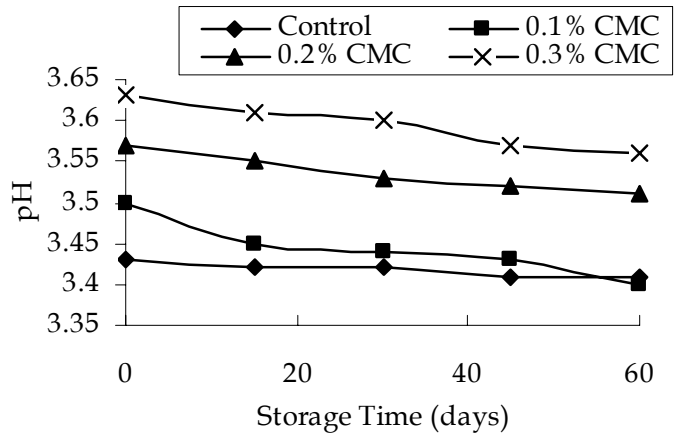

Fig. 3. Effect of different percentages of CMC on $\mathrm{pH}$ for various storage time

\section{Effect of starch on composition of tomato juice}

From Fig. 4 it was found that vitamin C (ascorbic acid) was reduced in tomato juice by the addition of increasing level of starch as well as with the increase of storage period, because it follows the first reaction kinetic (Heldman, 1974). So the content of' vitamin $\mathrm{C}$ of the final condition ( $1 \%$ starch) was very less compared with the control and other starch condition. 
Fig. 5 shows that $\mathrm{pH}$ level in tomato juice was increased with the addition of increasing level of starch, but it remained almost unchanged with the increase of storage period.

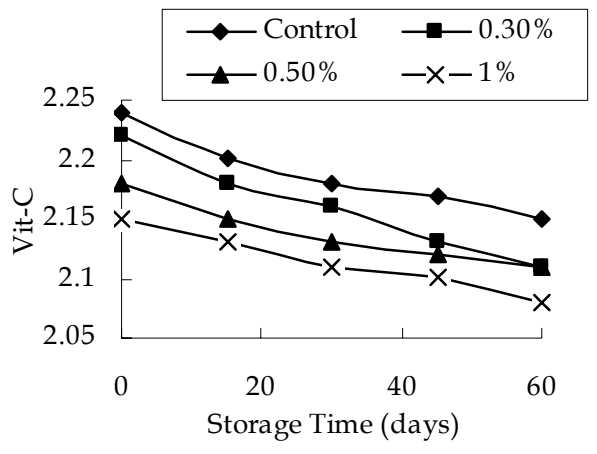

Fig. 4. Effect of different percentages of starch on Vit-C for various storage time

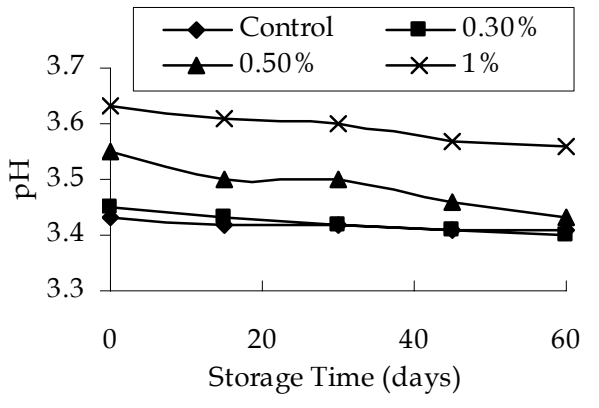

Fig. 5. Effect of different percentages of starch on $\mathrm{pH}$ for various storage time

\section{CONCLUSION}

Tomato juice was analyzed for TSS, $\mathrm{p}^{\mathrm{H}}$, Vit-C, moisture, total sugar, protein, fat and acidity. The compositions of initial tomato juice were investigated as moisture: $94.68 \%$, total sugar: $3.48 \%$, total ash: $0.41 \%$, protein : $1 \%$, fat : $0.1 \%$, ascorbic acid : $18.27 \mathrm{mg} / 100 \mathrm{~g}$, TSS: $4 \%$, acidity : $0.03 \%$ and $\mathrm{pH}: 4.01$. It was found that Vit-C in tomato juice was decreased for the addition of starch and CMC as well as storage period, whereas the $\mathrm{pH}$ was increased for the addition of both CMC and starch. The study has demonstrated that the addition of chickening agent such as CMC and starch increased the weight and volume of tomato juice which are considered important quality parameter for the products. CMC was found more suitable than the starch. According to the taste panel evaluation (Hedonic scale) of $0.1 \%$ CMC and $0.3 \%$ starch processed juices were highly acceptable. Quality of the product was improved when $0.3 \%$ starch was added.

\section{REFERENCES}

Anonymous. 1970. AOAC method: Official method of analysis, 11th edn., Association of official agricultural chemists, Washington, DC, USA.

Bhasin, U. R. and Bains, G. S. 1987. Journal of Food Science and Technology, India. 24(5) : 247-253.

Bose, T. K. 1985. Fruits of India: Tropical and Sub-Tropical, NAYA Prokash, Calcutta, India.

Cruess, W. V. 1958. Commercial fruit and vegetables products. McGraw Hill Book Company, New York, USA.

Heiser, C. N. 1969. The paradoxical plants. Treeman Co., Sanfransisco, USA.

Karmas, E. 1980. Techniques for measurement of moisture content of food. USA. Food Technol., 34(4) : 52-59. 
Kramer, A. and Twigg, B. A. 1968. Fundamentals of quality control for the food industry. Lane, J. H. and Eynon, L. 1923. Society of Chemical Industry, 42, 32T.

Lerman, F. E, Ivanenko, V. P. 1986. Pishehevaya I Pererabaty Vayuswhchaya Promyshlennost No. 8 : 39-40 [RO].

Ranganna, S. 1979. Mannual of analysis of fruit and vegetable products. Second Edition Tata McGrow Hill Publishing Company. New Delhi.

Sharfuddin, A. F. M. and Siddique, M. A. 1985. Sabjibijnan. 32, Bangladesh Agricultural University, Mymensingh, Bangladesh. 